\title{
Michael Handelsman: crítico desde y hacia la mitad del mundo
}

\author{
Michael Handelsman: a literary critic \\ from and towards the half of the World
}

\section{Manuel Medina}

Department of Classical and Modern Languages University of Louisville, Kentucky, Estados Unidos

DOI: https://doi.org/10.32719/13900102.2019.45.4

Fecha de recepción: 21 enero 2019

Fecha de aceptación: 27 marzo 2019 


\section{RESUMEN}

El presente artículo propone que el libro Guayaquil y sus escritores. Un homenaje a algunos clásicos que no se van publicado en el 2017 por Michael Handelsman, sirve como muestra de su esfuerzo por combatir el colonialismo académico impregnado entre círculos intelectuales elitistas. Sus análisis de literatura, revistas literarias y ensayos de autores ecuatorianos, se desarrollan dentro de un marco teórico de la interseccionalidad de Kimberlé Crenshaw que nos permite analizar las instituciones de control y poder. Este ensayo da ejemplos de cuatro estudios del Handelsman en donde se percibe su afán de intercalar a las letras ecuatorianas en el panorama global de la crítica y promover el reconocimiento del valor estético de obras que se desconocen debido tanto a actitudes exclusivistas como a pobres estrategias de difusión editorial.

Palabras Clave: Michael Handelsman, Ecuador, crítica, ensayo, colonialismo académico, interseccionalidad, control, poder.

\section{ABSTRACT}

This article states that the book entitled Guayaquil y sus escritores. Un homenaje a algunos clásicos que no se van, published in 2017 by Michael Handelsman, shows the author's effort to fight the academic colonialism enthroned by elitist intellectual circles. His analysis of Literature, literary magazines and essays on Ecuadorian authors, is developed within Kimberlé Crenshaw's inter-sectionalist theoretical framework, which allows us to analyze institutions that exert control and power. This essay provides examples of four studies by Handelsman, where his intention of interweaving Ecuadorian Literature within the global scene of critics can be perceived, as well as his intention to promote recognition of the aesthetic value of works unknown due to exclusivist attitudes and poor strategies of editorial distribution.

KEYwORDS: Michael Handelsman, Ecuador, critics, essay, academic colonialism, intersectionality, control, power.

DesDe los inicios de su carrera como crítico, Michael Handelsman se dedicó a promulgar la literatura del Ecuador entre los ámbitos intelectuales que la desconocían y no le otorgaban el lugar correspondiente dentro de las letras latinoamericanas. Sería difícil encontrar a otro intelectual que haya consagrado más de cuarenta años contiguos al estudio y difusión de la literatura del Ecuador dentro del contexto de la crítica global al punto de convertirse en referente obligado sobre los temas a los que se ha dedicado. El Distrito Metropolitano de Quito le entregó a Michael Handelsman la Medalla de Honor en reconocimiento por ser el crítico extranjero que más ha hecho por el estudio y la difusión de la literatura ecuatoriana fuera de las fronteras del Ecuador. Cabe enfatizar el gran logro que tal distinción representa, considerando que el Prof. Handelsman 
empezó como un joven crítico dictando conferencias y publicando en un medio que le dedicaba poco espacio a lo que tradicionalmente se ha considerado una producción cultural carente del nivel intelectual de las obras de autores y países etiquetados como más avanzados, o mas ricos, o el epíteto que se quiera usar para justificar la actitud colonialista que persiste en América del Norte:

Según mi condición de académico de Estados Unidos, enfocar mi trabajo como docente e investigador latinoamericanista en Guayaquil (o en Ecuador como tal), siempre requiere una especie de defensa de legitimidad académica. Es decir, dedicarse profesionalmente a estudiar con meticulosidad la literatura e historia cultural de una ciudad y un país cuya resonancia es mínima, por lo menos en mi país, siempre resulta conflictivo puesto que uno se ve obligado a insistir en la pertinencia de tales intereses dentro de una Academia que todavía funciona con su mentalidad colonial $(2017,14)$.

Michael Handelsman ha servido como pionero, y con su esfuerzo, ha directamente ayudado a cambiar esta actitud entre los intelectuales y estudiosos de la producción cultural de América Latina, a través de su prolífica obra dedicada al análisis de la ficción, el ensayo y las revistas literarias del Ecuador. Resulta crucial e imperativo afirmar que la Asociación de Ecuatorianistas representa un fruto de ese esfuerzo en su afán de encontrar un espacio propio para nuestra literatura. Reconocemos la obra de Michael Handelsman, y de sus abnegados colegas con quienes ha trabajado arduamente por el bien de la Asociación, entre los que mencionamos a Mike Waag, Antonio Sacoto, Tony Vetrano y Laura Hidalgo que dedicaron, y continúan dedicando su tiempo y energía a fortalecer esta Asociación que se mantiene fiel a su misión de promover el estudio de la literatura, la lengua y la cultura del Ecuador.

Sin ninguna duda los estudiosos de la literatura ecuatoriana y sus principales actores, los escritores, le debemos mucho a Michael Handelsman por haber desarrollado marcos teóricos que han forjado las conversaciones culturales sobre nuestras letras. Handelsman nos ha provisto con nuevas lecturas de los clásicos de la narrativa ecuatoriana y especialmente ha intercalado el análisis de la producción cultural ecuatoriana en el diálogo intelectual de críticos de la literatura latinoamericana en general. El canon diseñado por los discursos de control habían tradicionalmente incluido en sus historias panorámicas de las artes de la región mayormente al Grupo de Guayaquil, 
a Huasipungo de Jorge Icaza y La vida del ahorcado de Pablo Palacio. Comenzando con su primer libro Amazonas y artistas: un estudio de la prosa de la mujer ecuatorianas (1978) emplea un marco teórico feminista para darle inmediata jerarquía a la narrativa de nuestras grandes escritoras. Esta característica del trabajo crítico de Handelsman no se ha detenido ni cambiado a lo largo de su carrera. En su artículo sobre el vanguardismo transculturador de El rincón de los justos de Jorge Velazco Mackenzie, por ejemplo, la coloca en el espacio que le corresponde en la ficción latinoamericana que hasta entonces se lo había negado. La incluye en el canon de la narrativa latinoamericana junto a obras similares en calidad estética publicadas por escritores de otros países del continente. En su estudio de "La doble y única mujer" de Pablo Palacio, Handelsman argumenta que el cuento aboga porque se abra espacio a lo multicultural: "La doble y única mujer comprendía que su condición (ex)céntrica exigía un nuevo discurso filosófico que se abriera a una transformación social cimentada en la tolerancia y la justicia" (Handelsman 1995, 22). Los argumentos y conclusiones de este artículo se destacan como empleo perfecto de las lecturas innovadoras de un conocedor a fondo de nuestras letras y su habilidad como crítico agudo, preciso y perspicaz. Su análisis no cabe dentro de lo ortodoxo pero al mismo tiempo refleja la profundidad de su manejo de tanto la extensa obra primaria, las secundarias, la crítica sobre las obras y la teoría de crítica. Llegar a ese punto de dominio de las tres requiere dedicación y disciplina académica. En el presente ensayo leemos su producción empleando la teoría de la interseccionalidad de Kimberlé Williams Crenshaw para dar un recuento de la representación de Guayaquil en el trabajo analítico-intelectual de Michael Handelsman, relación que el mismo Handelsman ya ha indicado (2017, 15). Proponemos que su trabajo parcialmente recogido en Guayaquil y sus escritores: un bomenaje a algunos clásicos que no se van revela el proyecto académico de estudiar la literatura ecuatoriana desde un acercamiento de los estudios culturales bajo la constante de interpretar el arte como herramientas de promover "justicia social e inclusión" a lo largo de cuarenta años $(2017,17)$.

En general, el marco teórico para el estudio de la literatura ecuatoriana que Handelsman ha desarrollado ha evolucionado desde el feminismo, a estudios postcoloniales entre los que se incluyen los postulados sobre el concepto de identidad nacional. La constante en sus análisis representa estudiar cómo la literatura ha dado voz a los subalternos y ha establecido una tradición de crítica que respalda su posición y que se ha adaptado y nutrido 
de las diferentes tendencias de intelectuales dedicados a la interpretación del rol cultural de las letras. Nos referimos específicamente al concepto de políticas de identidad y su relación con conceptos dominantes de justicia social. Crenshaw sostiene que el discurso liberal trata las categorías de raza y género, entre otras, como vestigios de parcialidad y dominio. El poder social emplea estos elementos para excluir o marginalizar a los que son diferentes. La jurista formula que nuestro objetivo final de liberación debería concentrarse en borrar de estas categorías cualquier tipo de significado social que no permite que reluzcan diferencias que sobrepasan diferencias, tales como raza y clase. Da el ejemplo que las políticas de identidad han fracasado en considerar identidades interseccionales, tales como mujeres de color que resultan víctimas de machismo y sexismo ("Mapping the Margins"). Handelsman, aunque no usara el término porque no se había inventado al comienzo de su carrera sí llevó a cabo lecturas que reflejan la etiqueta propuesta por Crenshaw años más tarde. Handelsman habla de la intersección de raza y clase social, género y clase social, género y las clases de poder, raza y el ejercicio del poder, entre otras.

Guayaquil y sus escritores: un homenaje a algunos clásicos que no se van se publica en 2018 y sirve como excelente antología de la obra de Michael Handelsman. Se puede leer cronológicamente la evolución del intelectual en su trayecto de diálogo cultural con las letras del Ecuador. Obviamente, el libro se centra en sus ensayos sobre Guayaquil, aun así los textos incluidos sirven de modelo arqueológico, a la Foucault, de la progresión temporal de sus análisis. El epígrafe, proveniente de El rincón de los justos de Jorge Velasco Mackenzie, que Handelsman acertadamente escoge para el libro, resume el afecto especial que tiene hacia la ciudad donde ha pasado gran parte de su vida como investigador y donde empezara su trayectoria como estudioso de las letras y cultura del Ecuador. “[...] quien la busca la encuentra, quien la escucha la oye, quien la mira la ve y ya no podrá olvidarla nunca $[\ldots] "(2017,11)$. Desde el inicio del libro, Handelsman reafirma su identidad respecto a la urbe ecuatoriana: “[...] una ciudad que no es mía, pero que sí lo es” (11). Resaltamos que en la presentación de su estudio, Handelsman meditó sobre el paso del tiempo leído a través de los ensayos cuidadosamente seleccionados para el volumen y por sí mismo resume el común denominador de gran parte de su obra crítica: “[estos ensayos] adquirirán su pertinencia y pertenencia cuando las contemplamos desde simultáneos contextos no siempre armo- 
niosos, a saber: Guayaquil, Ecuador, América Latina, además del Sur y Norte globales en general" (13).

Fiel a su tendencia de incorporar teorías de crítica vigentes, una vez que las ha adaptado para analizar la literatura ecuatoriana, Handelsman ha dedicado mucho de su esfuerzo en promover, y estudiar la obra de Velasco Mackenzie, uno de los baluartes de la narrativa ecuatoriana contemporánea. En el capítulo titulado "Lo popular en el vanguardismo transculturador de Jorge Velasco Mackenzie", el crítico toma como punto de partida los postulados del vanguardismo en su postura subversiva de apartarse de los patrones europeos y proponer modelos propios de América Latina que permitan definir la literatura ecuatoriana desde una propuesta más autóctona: "Hemos de comprender el vanguardismo en el sentido de ruptura con un pasado falso e inauténtico, en el sentido de una creación de nuevas formas de definir lo latinoamericano" (96). Coloca la conversación justo en las contribuciones de intelectuales reconocidos como Hernán Vidal, Antonio Cornejo Polar, Carlos Monsiváis, Eduardo Galeano y Ángel Rama alrededor de la tesis que el vanguardismo estableció un vínculo claro entre lo político y lo estético, alejándolo de las posiciones elitistas de conectar al arte con las normas estéticas de superioridad del imperio, que continúan siendo sobreimpuestas por algunos críticos que las favorecen y privilegian (97).

Handelsman enlaza los emitidos del vanguardismo con el discurso anti-colonialista que ha apoyado a muchos escritores de América en sus propuestas estéticas que se enfrentan a las impuestas por el imperio. "Frente a las mentiras y los mitos propios del colonialismo, la explosividad histórico-social y sociopolítica de América ha encontrado una expresión efectiva en aquella escritura" (99). Michael Handelsman provee una larga lista de ejemplos de literatura ecuatoriana que cabe dentro de la definición del vanguardismo como la promulgan los críticos que menciona: "El Grupo de Guayaquil, Pablo Palacio, Hugo Mayo, Jorge Carrera Andrade, los integrantes del tzantzismo y La Bufanda del Sol, Jorge Enrique Adoum, Efraín Jara Idrovo, César Dávila Andrade, Miguel Donoso Pareja y un largo etcétera han sido constantes e incansables en su lucha por crear una literatura de rupturas y de transformaciones" (99-100).

A partir de este marco teórico, el crítico de la literatura ecuatoriana ubica a Jorge Velasco Mackenzie dentro del contexto de las letras latinoamericanas. Intercala a El rincón de los justos en el diálogo del vanguardis- 
mo, medido a partir del enlace entre la estética y lo político, lugar que le pertenece sin ninguna duda. Sin embargo, el modelo del mercado editorial que no facilita la circulación de novelas dentro de la misma América Latina le habían impedido que se la conozca fuera del territorio nacional o de contados países vecinos. Para sustentar su tesis, Handelsman añade el adjetivo "transculturador" al término vanguardismo y así afianza sus argumentos de manera estratégica para justificar el que una novela publicada en 1983 merezca esta clasificación. Al vanguardismo se lo cataloga como un movimiento que termina después del fin de la Segunda Guerra Mundial. Michael Handelsman propone primero, que la novela cabe dentro de la tradición vanguardista ecuatoriana que se inicia temprano en el siglo XX con la producción narrativa más reconocida del país y que Velasco Mackenzie continúa dentro de esta vertiente: “Es decir, por su condición de heredero de una tradición vanguardista nacional que data desde 1930, año en que se publicó Los que se van, Velasco se ha dedicado a la producción de una escritura moderna arraigada en el vanguardismo transculturador" (102). Afirma que esta "primera vanguardia ecuatoriana" colocó la conversación cultural dentro de una propuesta de otorgarle la voz a los menos representados de la sociedad, los subalternos: "De modo que, buena parte de la primera vanguardia ecuatoriana aceptó el reto de modernizar su discurso expresivo en el plano técnico mientras elaboraba contenidos cuya autenticidad giraba en torno a los sectores marginales" (103). Y allí nace la conexión entre ese "primer vanguardismo" y el "transculturador" definido así por Handelsman.

En sus postulados, el crítico de la literatura ecuatoriana enumera las razones que lo impulsan a vincular a Velasco Mackenzie con el primer vanguardismo y cita la relación de la novela con la presentación de los marginados por la sociedad como pieza clave de su disertación. "La marginalidad captada por Velasco -básicamente la de Guayaquil-, en cambio, emerge de una nueva visión que coloca a los olvidados urbanos en el centro mismo de la sociedad ecuatoriana" (105). Defiende su postura al enfatizar que esta gran obra narrativa se destaca dentro de la producción literaria que denuncia las condiciones de América Latina porque se aleja de los estereotipos de obras de esta índole que dan una mirada por encima. El rincón de los justos diluye la distancia que generalmente separa a narradores del material narrado: 
Pero el mundo popular de Velasco no se limita a pinceladas exteriores que hacen poco más que crear escenarios estáticos y estereotípicos. Vale anotar que pese a la legitimidad de la denuncia sociopolítica que marca gran parte de los textos solidarios con los sectores populares de América, en demasiados casos ha faltado una visión interior y dinámica capaz de borrar distancias entre narradores y mundos narrados (105).

Sobre lo "transculturador", Handelsman enuncia que la obra se antepone a la tendencia colonialista de la producción cultural de Ecuador que se enfoca en reproducir el mundo urbano de las altas esferas sociales. Y la obra de Velasco Mackenzie en su lugar le entrega la palabra a los del margen y de allí nace su valor y su postura vanguardista porque formula una nueva narrativa que les permite poder expresarse a los que tradicionalmente carecen de voz. La ciudad de Guayaquil que El rincón de los justos pinta a través de su narrativa corresponde a la que experimentan, respiran y viven la mayoría de sus habitantes. La novela le arrebata así la ciudad a los que aún detallan la ciudad sin incluir a los moradores de sectores de los escalafones menores de la estructura social y económica:

El lenguaje, la música y hasta la sensualidad de los personajes populares de Velasco se encuentran estrechamente vinculados a la experiencia cotidiana de gran parte de los guayaquileños. Es así que Velasco logra romper con algunas de las verdades oficiales del pasado -las que encubrían lo nacional a la vez que resaltaban los valores metropolitanos propios del colonialismo- y logra sugerir una nueva definición de identidad basada en la omnipresencia del pueblo. (Handelsman 2017, 105)

Handelsman cita la irreverencia hacia las instituciones de poder como un ejemplo del vanguardismo transculturador de la novela. Por ejemplo, entrega la escena en que una joven provee su propia versión del sincretismo al incorporar elementos de la oración sacrosanta de la religión católica del "Padre Nuestro" con sus deseos sexuales hacia su novio. Y reemplaza al tradicional Dios con su objeto de deseo, "Paco nuestro que estás en la tierra [...]". Se ha embarazado, sin haber cumplido los requisitos y mandamientos de la religión formal de casarse y formar una familia bajo las condiciones dictadas por el buen vivir. Además ella libremente expresa su pasión y sensualidad arrebatándole el discurso a los hombres a quienes la sociedad tradicionalmente les ha entregado el "derecho" de tratar el tema y se lo ha negado o restringido a las mujeres. 
La conclusión final de Handelsman respecto a El rincón de los justos altera el orden establecido por los patrones narrativos tradicionales al colocar al margen en el centro. Los personajes de los barrios de sectores populosos se levantan como protagonistas principales a los que se les permite expresarse en la novela empleando su lenguaje propio sin modificarlo para que corresponda a las normas tradicionales de hablar y expresarse. La novela le entrega la ciudad a sus verdaderos dueños:

Por consiguiente, en El rincón de los Justos Velasco Mackenzie se distingue por su visión cabal del lugar que realmente ocupa el pueblo en la ciudad. Con una lectura reflexiva dispuesta a reconciliar las apariencias con la realidad, paulatinamente el lector se da cuenta que el habla, la música, las supersticiones -en una palabra, la cultura- de Matavilela pertenece a todo Guayaquil. ¿Qué guayaquileño no sentirá la magia de los pasillos de J. J. (Julio Jaramillo)? ¿Quién no se identificará con el fútbol callejero o no se acordará del cine de su barrio? ¿Quién no habrá frecuentado los puestos de las revistas? (Handelsman 2017, 113).

Dentro de la propuesta vanguardista transculturadora, Handelsman plantea que la novela de Velasco Mackenzie obliga a redefinir fronteras al borrar las distancias rígidamente definidas que separan a los del centro con los del margen. La ciudad de Guayaquil pertenece a todos:

Sin centros que se opongan a periferias, sin privilegiados que se distancien de marginados, la visión que Velasco tiene de su Guayaquil sugiere una totalidad cuya riqueza y nobleza vienen de un pueblo guayaquileño heterogéneo y abigarrado que se niega a ser olvidado. De hecho, mientras evita romanticismos gratuitos y pasatistas, Velasco Mackenzie evoca una ciudad multifacética y compleja $(2017,115)$.

Handelsman demuestra con su lúcida argumentación que El rincón de los justos como las obras de vanguardia se sirve de lo estético para darnos una literatura de combate que presenta un modelo social que favorece a los marginados al colocarlos en el centro de la narración y como protagonistas principales de esta gran urbe. Y el crítico sitúa así a la novela dentro de la conversación cultural sobre el tema que se ha venido desarrollando en América Latina. Así El rincón de los justos, gracias al esfuerzo de Michael Handelsman, recibe su lugar merecido en la historia de la literatura: 
Es decir, pese al silencio y el desconocimiento que tienden a relegar a la literatura ecuatoriana a una periferia cultural vis-à-vis ciertos centros de América Latina, quisiera insistir una vez más que El rincón de los justos y la obra en general de Velasco Mackenzie -entre la de otros compañeros del Ecuador- trascienden fronteras nacionales y pertenecen plenamente a una novelística latinoamericana [...] $(2017,116)$.

Tal como lo había expresado Ángel Rama al hablar de la literatura de combate, vanguardista, de la región.

El ensayo en que se analiza la labor cultural de Carlos Calderón Chico se sirve de un enfoque postcolonialista que mantiene la vertiente latente en la obra de Michael Handelsman como venimos demostrando. Carlos Calderón Chico constituyó un baluarte de la promoción de la cultura ecuatoriana, con un énfasis en la guayaquileña. Handelsman describe el corpus de obra de Calderón Chico como un esfuerzo militante que emplea la producción cultural como herramientas de protesta en contra de la falta de equidad sostenida por el sistema establecido que privilegia las clases que controlan el poder adquisitivo y político:

Frente a todos los obstáculos, Calderón Chico realiza una labor cultural dinámica que ha convertido el libro, la literatura y la investigación en instrumentos de lucha social. Lejos de elitismos y torremarfilistas, el concepto que Calderón Chico tiene de cultura -su modus vivendi si se quiere- está profundamente arraigado en una tradición de cuestionamiento, de indagación y de búsqueda que promete conducirnos eventualmente hacia la descolonización definitiva de toda Latinoamérica. $(2017,72)$

Handelsman encuentra en el trabajo literario de Carlos Calderón Chico el denominador común de intentar subvertir el status quo enfrentándose a los postulados tradicionales que simplemente respaldan actitudes implantadas a lo largo de los tiempos. Formula que se impone y dedica a tres tareas básicas relacionadas directamente con la literatura del Ecuador y el regionalismo agobiante que la encapsula, la difusión de las letras nacionales en el contexto internacional, y emplear su crítica y las revistas culturales para despertar la conciencia política a través de la estética de las artes. Al hablar de América Latina, los intelectuales internacionales se limitan a las súper estrellas que aparecen publicadas y traducidas a las lenguas francas, tales como el inglés y el francés. Debido a la cobertura global resulta difícil competir con escritores establecidos aunque los escritores y 
las obras ignoradas por la prensa cultural y los círculos intelectuales ofrezcan técnicas narrativas o estéticas innovadoras que hasta sobrepasen a las renombradas en el mundo:

Mientras los medios internacionales de comunicación tienden a reducir el mundo cultural de América a unas pocas figuras torales -Paz, Vargas Llosa, García Márquez, por ejemplo- o lo limitan a unos títulos proclamados best sellers por ciertos centros metropolitanos, en todas partes se pierde de vista el verdadero sentido y la auténtica razón de ser de la labor de muchos que producen cultura en América Latina (72).

Carlos Calderón Chico adopta una actitud de combate hacia esta actitud colonialista y le devuelve al arte el rol marxista que le otorga al artista y su obra, un rol primordial en el desarrollo de la conciencia social. Y lucha contra el proceso de mitificar a escritores cuya cobertura perjudica, opaca o simplemente ignora la obra de escritores de gran valor. Su labor social radica en insertar a las grandes escritores ecuatorianos dentro del panorama global por medio de sus revistas y otra obra de difusión en un afán de reformar las políticas del establecimiento del canon, como lo sugiere Handelsman: "Lo que es primordialmente un proyecto de lucha y de descolonización, lo que constituye un compromiso para realizar verdaderas transformaciones sociales y lo que surge muchas veces entre penurias y persecuciones se ha querido identificar con eventos de taquilla en vez de con combates de trinchera" (73). Emplea la crítica como un arma, a la manera de los directores brasileños del Cinema Novo de los sesenta.

Handelsman nota que Carlos se embarca en una tarea que hace falta en todo el continente, en donde en cada país encontramos grandes autores y periodistas culturales que viven en completo anonimato tanto dentro como fuera de sus países debido a las políticas gubernamentales que reflejan las que Calderón Chico intenta reformar con su obra de promoción:

El anonimato en que vive fuera de su país y el silencio en que trabaja dentro del Ecuador mismo representan la experiencia de miles y miles de trabajadores culturales de todo el continente [...]. Carlos Calderón Chico de Guayaquil realiza su obra cultural como un acto de reivindicación y descubrimiento tanto nacionales como continentales (73-4).

La revista Puño y Letra, de la que solo circularan dos números, ya que el tercero se censuró debido al contenido, refleja, según Michael 
Handelsman, la ideología en procura de un cambio a la profesión y en la manera de realizar periodismo cultural de esta envergadura. Lo que nunca cesaría de aparecer como elemento común de toda su obra crítica. Handelsman enfatiza la relevancia de una revista que logra incorporar a escritores de gran talento y reconocimiento. Señala el tino de Calderón Chico al reconocer el talento artístico de escritores que recién comenzaban su carrera y que eventualmente se convirtieron en autores reconocidos en el ámbito (77). El crítico estadunidense igualmente indica el empeño de Calderón Chico de combatir contra el regionalismo incrustado en la identidad nacional. Su labor cultural representa la revista como una obra digna de mencionarse por establecer vínculos entre escritores de diferentes sectores del país:

Frente al eterno problema de aislamiento y regionalismo, tanto a nivel nacional como a nivel latinoamericano, Calderón Chico arma una revista que pretende poner al lector guayaquileño en contacto con importantes escritores de la sierra ecuatoriana y del exterior. Tender puentes, informarse, dialogar y conocerse son los componentes de esta orientación amplia y abierta que Calderón Chico dirige contra toda fragmentación y balcanización cultural, y que ya se vislumbra en Puño y Letra (78).

En efecto, esta primera incursión de Carlos Calderón Chico en el mundo de las revistas literarias va a marcar profundamente todo el aporte cultural que él realizará posteriormente a lo largo de su prestigiosa carrera. Handelsman la resume como un afán de “descolonizar a América” (84). Y da una lista de las preocupaciones que perseveran en todo su material publicado, sea entrevistas a autores o crítica de sus textos: "La responsabilidad social del escritor, la penetración cultural, el problema de la periodización, la política cultural y el Estado, el exilio y la literatura infantil son la sustancia medular de los diálogos" (84). Concluye su estudio de la obra de Carlos Calderón Chico enmarcando dentro del membrete del rol social del intelectual de América Latina que debe luchar contra las fuerzas colonialistas e imperialistas y valerse de la producción cultural como herramienta ideal para su tarea: "Inmerso en una ciudad de enormes problemas sociales, consciente de las transformaciones que todavía quedan por hacer en todo el continente, este trabajador de cultura de Guayaquil pertenece a una larga tradición combativa que emplea el libro -y la actividad cultural, en general- como una incitación para cambiar la realidad" (94). 
En el artículo que abre la sección de ensayos del libro que estudiamos "La prosa feminista de las revistas de los años 30. El caso de Nuevos Horizontes de Guayaquil (1933-1937)", Handelsman debate sobre el valor y rol de voces femeninas guayaquileñas, aunque privilegiadas, guiadas por Rosa Borja de Icaza en la lucha por demandar más derechos para la mujer. La revista sirvió para difundir la labor de La Legión Femenina de Educación Popular. Se destacó por promover y adelantar la causa de la defensa de los derechos de la mujer en el país. En el ensayo más extenso que aparece originalmente en Letras Femeninas, se habla del privilegio y la opresión representados en las instituciones del machismo y el marianismo respectivamente. Handelsman sugiere que las mujeres emplearon la revista como portavoz de sus propuestas progresistas que operaban aún dentro de ideologías conservadoras con tendencias liberales: "En efecto, las feministas ecuatorianas no ansiaban mejores oportunidades educacionales y profesionales para abandonar sus roles tradicionales, sino más bien para llevarlos a cabo con mejores resultados" (Handelsman 1978, t. I, 63). Lucharon por derechos específicos en procura de igualdad de opciones: "Por eso, el sufragio, más participación en la política, iguales oportunidades y reformas legales se hicieron temas populares entre las más destacadas escritoras del Ecuador durante los años previos a la Segunda Guerra Mundial” (66). Handelsman ubica este argumento dentro del que la Revolución Liberal había creado un clima propicio para avances de las causas sociales de los derechos de la mujer. Ecuador representa el primer país de América Latina que le otorga el derecho al voto a la mujer, en 1929. Pero los grupos conservadores constantemente trataron de arrebatárselo. En el capítulo del libro, Handelsman cita el triunfo del movimiento liberal como punto de partida para que las mujeres puedan expresarse y promover sus plataformas ideológicas: "De hecho, para muchos ecuatorianos, los intentos de los liberales de mejorar la situación social de las mujeres representaban una amenaza a un orden establecido que por mucho tiempo se había considerado sagrado (i.e., el matrimonio, la maternidad y la virginidad)" (23).

Handelsman se sirve de su ensayo para colocar a la revista Nuevos Horizontes dentro del contexto de la lucha por los derechos de los menos privilegiados. Y lee la revista bajo lo que desde una perspectiva del siglo veintiuno tildamos del concepto de políticas de identidad y su relación con conceptos dominantes de justicia social de Kimberlé Williams Crenshaw. El crítico estudia a las escritoras de Nuevos Horizontes bajo la categoría de 
mujeres que luchan contra el privilegio del patriarcado, a pesar de pertenecer al grupo de dominio del poder económico. Explica cómo se unieron a las mujeres de clases menos pudientes con proyectos de beneficio común: "No es de extrañar entonces que Nuevos Horizontes haya sido caracterizada por una gran amplitud de preocupaciones e intereses que incluía, por ejemplo, campañas de alfabetización, legislación especial para proteger a las trabajadoras y a los niños, la enseñanza para la mujer, el panamericanismo y la paz mundial” $(2017,27)$.

Handelsman plantea que la revista permitió que las mujeres pudieran escribir y publicar en una sociedad que les obstaculizaba tal derecho y cita el ejemplo de María Esther Martínez y su ensayo "El problema feminista en el Ecuador", donde invita a las mujeres a organizarse al mismo tiempo que le pide al gobierno la creación de asociaciones que se dediquen exclusivamente a debatir y defender los derechos de las mujeres. Martínez enfatiza la posición del movimiento a fin de calmar a lo establecido que se siente amenazado y renuente a apoyar su causa (31-2). El crítico estima que allí yace su valor y contribución a la causa del movimiento feminista y a la sociedad en general. Pero, sobre todo, Nuevos Horizontes dio a las mujeres la oportunidad de escribir. Puesto que se creía que las perspectivas masculinas habían sido formadas por circunstancias específicas y exclusivas a las realidades del hombre, muchas ecuatorianas se dieron cuenta de que resultaba esencial que ellas mismas también interpretaran públicamente sus propias experiencias singulares. Por eso, aceptaron el desafío de defender a la mujer y darle a conocer a esta el camino hacia nuevos horizontes.

Comentemos otro capítulo del libro Guayaquil y sus escritores: un homenaje a algunos clásicos que no se van. En "La misión cultural de un suplemento literario de Guayaquil”, mantiene la propuesta ideológica del texto sobre la revista Nuevos Horizontes recién analizado. Handelsman explica que se ha dedicado a estudiar esta publicación debido a que su misión difiere grandemente de la de obras similares que aparecen semanalmente en los periódicos de mayor circulación de las mayores urbes del país. Su tesis principal parte de la siguiente premisa: "El Meridiano Cultural constituye una ruptura con el pasado" $(2017,54)$. Y su contenido se origina a consecuencia del esfuerzo deliberado de sus colaboradores que operan bajo una misión específica de "reivindicación de los valores populares ecuatorianos" (54). El autor enfatiza que se plantee una política editorial que vuelva el arte y la cultura ecuatorianas accesibles al pueblo y que se 
base en un intercambio entre intelectuales y la audiencia masiva y popular. El suplemento se coloca dentro de un ciclo natural que da por sentado que las obras nacen del pueblo y deben de regresar a él, su creador (54).

A Handelsman le entusiasma este propósito de extender la interpretación y crítica literaria de alta calidad intelectual a las masas y extraerlos de esferas elitistas que lo habían controlado hasta entonces: "El Meridiano Cultural participa en un proyecto latinoamericano de producir y fomentar conceptos liberadores del arte que hasta ahora ha sido confinado a santuarios y salones privados" (55). Handelsman añade el argumento de que la interpretación de la literatura y las artes en general operan bajo una tradición que limita a sus actores y que privilegia a un número limitado de estudiosos que deben ceñirse a las normas de exclusión tácitamente, aunque sutilmente, impuestas por el discurso oficial: “De modo que, muchos jóvenes del Ecuador -si se puede generalizar de una mesa redonda- siguen perteneciendo a una tradición colonialista cuyo concepto de Cultura oficial ofusca otras perspectivas de interpretación y reconocimiento" (59). Aplaude el que dentro de esta atmósfera oficial exclusivista y las notas culturales que se difunde en suplementos de los diarios, El Meridiano Cultural surge como opción notable:

Ante esta situación, un suplemento como El Meridiano Cultural se vuelve valioso. Si bien es cierto que dentro de los círculos oficiales, los lectores se nutren de una literatura adormecedora y, que por otra parte, los medios de comunicación masiva cultivan la mediocridad y el conformismo, es de notar que cada sábado en Guayaquil (y en otros puntos de circulación en el Ecuador) existe la posibilidad de encontrar una alternativa. (61)

No obstante, los objetos de estudio y por ende el contenido de los artículos de El Suplemento Cultural constituye el tema que más impresiona al crítico estadounidense. Sus comentarios caben perfectamente dentro de la constante de su afán por promover la obra del subalterno y grupos sub-representados. Según Handelsman, los artículos permiten la presencia de una dualidad de voces en donde se borra la línea divisoria que marca la supremacía de la alta cultura sobre la cultura popular. Y entrega una lista de los temas de estudio como evidencia: "La galería de personas que aparece en El Meridiano Cultural incluye a Shakespeare, Pound, Brecht, Freud, Marx, Einstein, García Márquez, Neruda, Borges. También se encuentra a Celia Cruz, Rubén Blades, Daniel Santos y Benny Moré. Siempre el punto y el 
contrapunto, lo supuestamente culto y lo popular" (64-5). Y expone que los autores de los textos de análisis se abstienen de favorecer a una forma de arte sobre otra simplemente porque provienen de diferentes entornos creativos: "En vez de haber un conflicto o una contradicción entre comentarios sobre la salsa caribeña y el cubismo de las artes plásticas por ejemplo, emerge más bien una coherencia de ideas y propósitos" (59-64). Se trata con el mismo repecto y curiosidad intelectual a todas las manifestaciones creativas y culturales:

Cada artículo, cada comentario y cada informe sirven para acercar los polos opuestos. Sin considerar los materiales de cultura popular indignos de respeto, y sin fetichizar los valores y méritos de los materiales más intelectualizados, los colaboradores del suplemento han producido un instrumento cultural basado en la complementariedad y solidaridad orientado hacia la transformación de una sociedad que no representa los intereses heterogéneos de la mayoría nacional (64).

Concluye reafirmando la novedad y más que todo el valor de este proyecto de descolonización de la cultura que se la arrebata a las elites que las han controlado por tanto tiempo en una especie de acto de liberación cultural. Handelsman predice la repercusión positiva de la misión y función de este suplemento dentro del desarrollo intelectual de las letras, la cultural y su crítica y apreciación estética por su afán igualitario de proporcional acceso masivo: "El Meridiano Cultural fomenta el cuestionamiento ya que pretende desenmascarar los defectos del orden actual mientras tiende puentes entre sectores sociales tradicionalmente adversarios” (51).

Después de tener el privilegio de estudiar el conjunto de la obra crítica de Michael Handelsman concluimos que su trabajo investigativo revela que ha concentrado su esfuerzo como académico en insertar a las letras del Ecuador dentro del ambiente académico global. Y ha logrado gran éxito si lo evaluamos desde su prolífica producción publicada en revistas profesionales y libros en editoriales de diversos continentes; además ha servido de mentor y ejemplo para las generaciones actuales que seguimos su modelo. Handelsman reconoce que sus logros se han derivado y nutrido precisamente de esa conversación entre intelectuales del Ecuador y de Estados Unidos, escritores, críticos, alumnos, profesores y demás. Estos diálogos le han permitido acercarse una y otra vez a los clásicos de la literatura ecuatoriana en procura de nuevos niveles semánticos pro- 
venientes de nuevas lecturas provocadas a menudo por ese intercambio: "Sencillamente, ellos no se van y, por eso, los llamo clásicos porque su producción creativa sigue llamándome y con cada nueva lectura construyo nuevos significados cuya pertinencia y pertenencia me (re)construyen a mí como lector, académico y persona siempre en diálogo con los de aquí y de allá" (18). *

\section{Bibliografía}

Crenshaw, Kimberlé. 2015. "Demarginalizing the Intersection of Race and Sex: A Black Feminist Critique of Antidiscrimination Doctrine, Feminist Theory and Antiracist Politics". The University of Chicago Legal Forum 1989.1.

Handelsman, Michael. 1978. Amazonas y artistas: un estudio de la prosa de la mujer ecuatoriana. Colección Letras del Ecuador. Vol. 70-71. Guayaquil: Casa de la Cultura Ecuatoriana, Núcleo del Guayas.

—. 1990. "Lo popular en el vanguardismo transculturador de Jorge Velasco MacKenzie: Un análisis de El rincón de los justos". Chasqui 19.1: 24-31.

—. 1995. "Una doble y única lectura de 'Una doble y única mujer' de Pablo Palacio". Chasqui 24.2: 3-23.

—.2017. Guayaquil y sus escritores: un homenaje a algunos clásicos que no se van. Colección del bicentenario de la independencia de Guayaquil. Tomo IV. Guayaquil: Club de La Unión. 